\title{
Reserves of Generating Capacity for Perspective Planning of Development of the Unified Energy System of Russia
}

\author{
Dmitry Krupenev ${ }^{1 *}$, Denis Boyarkin ${ }^{1}$, Dmitrii Iakubovskii ${ }^{1}$, Gennady Kovalev ${ }^{1}$, and Ludmila Lebedeva ${ }^{1}$ \\ ${ }^{1}$ Melentiev Energy Systems Institute of SB RAS, Energy Security Department, 664033 Lermontov str. 130, Russia
}

\begin{abstract}
Determination of reserves of generating capacity is one of the main tasks in planning the future development of electric power systems. There are many problems that affect the rational level of redundancy of generating capacities in Russian power industry. Modern changes in the Russian electric power industry concerning the level of redundancy of generating capacity in the long-term planning of the development of the Unified Power System (UPS) of Russia are analyzed in the article. The optimization problem of determining the necessary reserves of generating capacity in the power system, based on the assessment of adequacy, taking into account the modern features of the development of the UPS of Russia is presented. The results of assessing the adequacy of the UPS of Russia at the level of 2022 and the value of the optimized reserves of generating capacity in the UPS of Russia are showed in the final part.
\end{abstract}

\section{Introduction}

The problem of determining the rational level of redundancy of generating capacities is one of the main ones in the long-term planning of power systems development [1]. The reserve of generating capacities in the power system should have an optimal value corresponding to the technical and economic criterion. Many factors influence on determination of the level of optimal redundancy of generating capacity. Among the main ones are the level of accidents in power equipment, the rules for scheduled repairs of power equipment, the development of the electric network, the amount of damage to consumers from insufficient reliability of the power system. The main criterion for solving the problem of optimal reserves of generating capacity of the electric power system (EPS) is to minimize the amount of costs to increase the reliability of the EPS and the damages resulting from insufficient reliability of the EPS [2-4].

A wide range of indicators is determined in adequacy assessment. They are associated with damage and characterize the level of reliability of the power system. The probability of deficit-free operation can be used instead of using damage from low reliability in the problem of optimal reservation of generating capacity. In the main, the probability of deficit-free operation is used as an additional constraint [4]. This formulation of the problem is equivalent to a formulation with a damage; moreover, with this formulation, it is possible to take into account possible requirements from electricity consumers in ensuring the standard level of reliability of power supply.

It is advisable to substantiate the level of reserves of generating capacity in accordance with the development of the network part of the power system. In terms of ensuring the reliability of electricity consumers, these technological links are connected in series and the overestimated reliability of one of the links will not lead to the effect of ensuring the required level of reliability of electricity consumers [5].

The amount of generating capacity reserves influence to many strategic mechanisms for the development of the power system. For example, within the framework of the capacity market, the main mechanism is competitive power take-off (CPT) [6]. The amount of the generating capacity reserve is included in the demand for capacity during the CPT and, accordingly, directly affects the final price of capacity. As a first approximation, for the first price zone of the Unified Power System (UPS) of Russia, a decrease in demand and, accordingly, in the amount of the generating capacity reserve by $5 \%$ will lead to a decrease in the price during CPT by $15 \%$, and in the second price zone of the UPS of Russia, a decrease in demand by $5 \%$ may lead to a $12 \%$ decrease in the price CPT.

At the present stage of the development of the electric power industry in Russia, a number of various problems have accumulated in the EPS of Russia. One of the essential is significant volumes of morally and physically obsolete generating capacities [7]. Combined with low demand for power from consumers and problems with old capacity, the efficiency of the power system is extremely low. In addition, in modern conditions of the functioning and development of power systems, the uncertainty in power generation increases due to the integration of renewable energy sources into the power system, which makes the task of determining the optimal level of reserves even more urgent [8].

\footnotetext{
* Corresponding author: krupenev@isem.irk.ru
} 
In addition, in the legislative framework of the Russian Federation, the requirements for the levels of reserves of generating capacity in the UPS of Russia are not clearly formulated, and in some documents, they contradict each other. Work is currently underway to eliminate this deficiency at present time.

\section{Problem statement}

When determining the level of redundancy of generating capacity, an important factor is the selection and justification of the criterion of redundancy. Adequacy indices are used as such a criterion. Obtaining adequacy indices is carried out using a technique based on the Monte Carlo method $[9,10]$. In this case, the power system, as a rule, is represented as a set of reliability zones connected by inter-zone connections. The reliability zone is a part of the power system within which there are no power limitations in all possible steady-states. Inter-zone communication is a set of transmission lines that connect two identical zones of reliability. In the power system, there is a concept as a controlled section. The controlled section is a set of power transmission lines for which the maximum permissible active power flow has been determined. In the design scheme for adequacy assessment, the inter-zone connection and the controlled cross-section may not coincide; in this case, when minimizing the power deficit, it is necessary to use special algorithms to take into account the network component [11].

As already noted, the probability of a deficit-free operation can be taken as a criterion for ensuring adequacy $[9,12]$. To substantiate the normative value of this indicator, a methodology has been developed, which is presented in [13].

As mentioned above, the current state of the UPS of Russia is characterized by surpluses of old and inefficient generating capacities, with local problems in some power regions. Therefore, the task for the study was formulated as the task of minimizing the available power of the EPS, corresponding to the standard level of probability of deficit-free operation, taking into account the decommissioning of the existing generating units.

The considered problem is:

$$
\sum_{j=1}^{J} x_{j} \xi_{j} \rightarrow \min
$$

where constant $x_{j}$ - available capacity of the existing generating unit $j ; J$ is the number of generating units in the EPS; the variable $\xi_{j} \in\{0,1\}$ is a sign of the presence of the generating unit $j$ as part of the EPS generation.

Variables constraints:

$$
\left\{\begin{array}{l}
P_{i} \geq P_{\text {norm }}, \text { если } P_{\text {init }, i} \geq P_{\text {norm }} \\
P_{i} \geq P_{\text {init }, i}, \text { если } P_{\text {init }, i}<P_{\text {norm }}
\end{array}, i=1, \ldots, I,\right.
$$

where $P_{i}$ is the probability of deficit-free operation in the $i$ reliability zone, $I$ is the number of reliability zones in the EPS; $P_{\text {norm }}$ - standard level of probability of deficit-free operation in EPS; $P_{\text {init }, i}$ - the probability of deficit-free work in the reliability zone $i$ for the initial version.
The $P_{i}$ values for $i=1, \ldots, I$ are calculated by evaluating the balance reliability of EPS $\left(F_{i}\right)$ for the current composition of generating units.

$$
P_{i}=F_{i}(\xi), i=1, \ldots, I \text {. }
$$

\section{Experimental investigation}

When preparing the initial data for the research, a significant amount of statistical data on the operation of the equipment of the UPS of Russia was processed. The study was carried out for the development plans of the UPS of Russia for 2022 [14]. When clustering the UPS of Russia, 106 safety zones were identified. The variant of development of the UPS of Russia, presented in [14], was characterized by the data of the energy balance per hour of the coincident maximum power demand, presented in Table 1. Table 2 presents the data on the energy balance for parts of the UPS of Russia within the boundaries of interconnected power systems (IPS). When clustering the UPS of Russia into reliability zones, the Smolensk energy system was assigned to the $13 \mathrm{NW}$ reliability zone. This zone is part of the Nord-West IPS, although the Smolensk energy system is in fact part of the Central IES. In the results, all the parameters characterizing the Smolensk energy system are presented in the initial data of the IPS of the North-West, namely its own maximum power consumption, which in 2022 is equal to $1086 \mathrm{MW}$, other characteristics of power consumption, generating units with their characteristics, the capacity of which is 3995 MW.

Table 1. Power balance in the UPS of Russia at the level of 2022 (initial version)

\begin{tabular}{|c|c|}
\hline Installed capacity, MW & 236442 \\
\hline Installed capacity limitations, MW & 18341 \\
\hline Available capacity $x_{U E S}, \mathrm{MW}$ & 218101 \\
\hline $\begin{array}{c}\text { Coincident maximum power } \\
\text { demand } y_{U E S}, \mathrm{MW}\end{array}$ & 165202 \\
\hline $\begin{array}{c}\text { Capacity reserve, } \% \\
\left.\left(x_{U E S}-y_{U E S}\right) / y_{U E S}\right)\end{array}$ & 32 \\
\hline
\end{tabular}

Table 2. Power balance in the UPS of Russia at the level of 2022 (initial version)

\begin{tabular}{|c|c|c|c|}
\hline $\begin{array}{c}\text { EPS } \\
\text { Name }\end{array}$ & $\begin{array}{c}\text { Available } \\
\text { capacity, } \\
\text { MW }\end{array}$ & $\begin{array}{c}\text { Coincident } \\
\text { maximum } \\
\text { power } \\
\text { demand, MW } \\
\text { (with UPS of } \\
\text { Russia) }\end{array}$ & $\begin{array}{c}\text { Capacity } \\
\text { reserve, } \\
\%\end{array}$ \\
\hline $\begin{array}{c}\text { Nord- } \\
\text { West } \\
\text { IPS }\end{array}$ & 25634 & 16470 & 55 \\
\hline $\begin{array}{c}\text { Central } \\
\text { IPS }\end{array}$ & 43797 & 37120 & 18 \\
\hline
\end{tabular}




\begin{tabular}{|c|c|c|c|}
\hline $\begin{array}{c}\text { South } \\
\text { IPS }\end{array}$ & 21794 & 17840 & 22 \\
\hline $\begin{array}{c}\text { Middle } \\
\text { Volga } \\
\text { IPS }\end{array}$ & 25181 & 16953 & 43 \\
\hline Ural IPS & 51309 & 38820 & 32 \\
\hline $\begin{array}{c}\text { Siberia } \\
\text { IPS }\end{array}$ & 38544 & 31483 & 22 \\
\hline East IPS & 11843 & $7137^{*}$ & 66 \\
\hline
\end{tabular}

* IPS of the East operates in isolation from the UPS of Russia, using its own maximum power consumption.

As can be seen from Tables 1 and 2, the level of generating capacity redundancy in the UPS of Russia and, particularly, in IPSs is high. If we compare the presented values of capacity reserves with the values presented in [15], we can see that, for example, recommended value for the IPS of Siberia is $12 \%$ [15], instead of the real $22 \%$. Moreover, when determining the actual reserve ratio, all limitations were taken into account, including hydroelectric power stations output limitations.

The UPS of Russia was divided into reliability zones as part of an adequacy assessment. Each reliability zone was assigned an index and a conditional name. After adequacy assessment of the initial variant of the UPS of Russia development, it was determined that the probability of deficit-free operation in almost all 106 reliability zones turned out to be higher than the standard level, with the exception of:

1. Reliability zone $8 \mathrm{NW}$ (NW - Nord-West), covering the energy region in the North-West IPS. In fig. 1 shows the energy balance in the area of the $8 \mathrm{NW}$ reliability zone. The probability of deficit-free work in this area was 0.9955 .

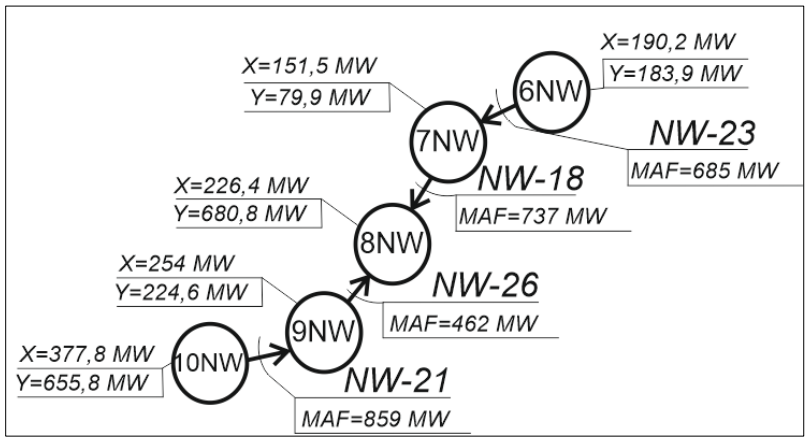

Fig. 1. Power balance of $8 \mathrm{NW}$ and adjacent reliability zones. ( $\mathrm{X}$ is the available power, $\mathrm{Y}$ is the power consumption).

When analyzing the balance situation around the $8 \mathrm{NW}$ reliability zone, it was determined that the network capabilities of the controlled sections connecting the $8 \mathrm{NW}$ with other reliability zones are sufficient to cover the power deficit in the $8 \mathrm{NW}$ even in the event of a failure of one of the network elements affecting the maximum allowable flow (MAF) of the controlled sections. However, the generating capacity capabilities of the reliability zones adjacent to the $8 \mathrm{NW}$ are not sufficient to cover the capacity deficit in the $8 \mathrm{NW}$. Thus, we can conclude that power shortages during the billing period with a high probability may arise due to the lack of generating capacities in the considered power region and the "weak" transit of power from the power system of the Leningrad oblast.

2. Reliability zone 4S (S - South) is part of the power system of the Rostov oblast. The probability of a deficitfree operation of this reliability zone was 0.9968 , which is lower than the accepted standard. In fig. 2 shows the energy balance in the 4th and in the adjacent reliability zones. The own maximum power consumption of the considered reliability zone is $2782.8 \mathrm{MW}$, and the value of the available capacity within the reliability zone is 640.1 MW, thus the own deficit of $4 \mathrm{~S}$ is $2142.7 \mathrm{MW}$. The $4 \mathrm{~S}$ reliability zone is connected to the $7 \mathrm{~S}$ reliability zone by two $220 \mathrm{kV}$ power lines and $500 \mathrm{kV}$ power lines, which are included in several controlled sections; to the $5 \mathrm{~S}$ is connected by $220 \mathrm{kV}$ transmission line and two $500 \mathrm{kV}$ transmission lines, also included in several controlled sections; to the $1 \mathrm{~S}$ by $220 \mathrm{kV}$ transmission lines and 500 $\mathrm{kV}$ transmission lines included in several controlled sections; with a reliability zone of $14 \mathrm{~S} 500 \mathrm{kV}$ transmission lines included in several controlled sections. Figure 2 shows the power balance of the $4 \mathrm{~S}$ and adjacent reliability zones.

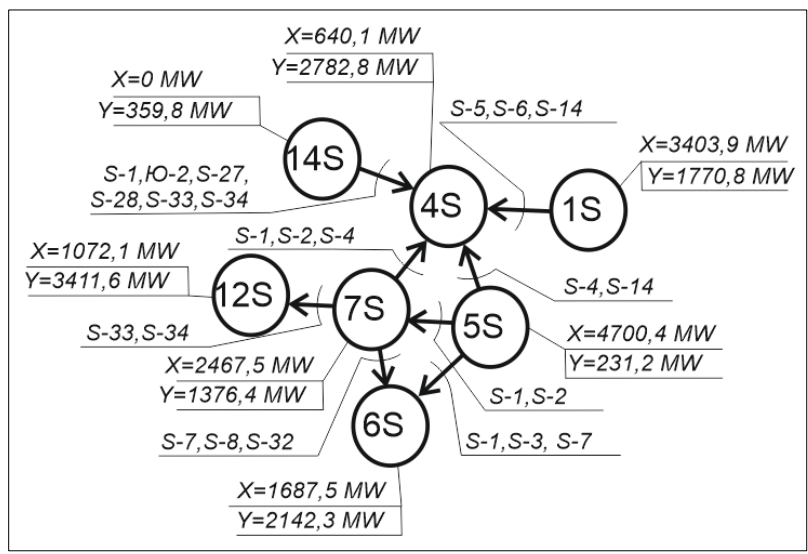

Fig. 2. Power balance of $4 \mathrm{~S}$ and adjacent reliability zones.

When considering the balance situation of the $4 \mathrm{~S}$ reliability zone, we can conclude that the generating capacity of the neighboring reliability zones and the transmission capacity of the transmission lines connecting the $4 \mathrm{~S}$ with neighboring reliability zones should be sufficient to cover the power deficit in $4 \mathrm{~S}$. However, a number of reliability zones, including $6 \mathrm{~S}$ and $12 \mathrm{~S}$ connected to $7 \mathrm{~S}$, are also in short supply. The main donor zones for $4 \mathrm{~S}$ are $1 \mathrm{~S}$ and $5 \mathrm{~S}$. The main controlled section limiting the transfer of power from $1 \mathrm{~S}$ and $5 \mathrm{~S}$ to $4 \mathrm{~S}$ is $\mathrm{S}$ 14. In the event of failure of one of the power lines of the section S-14, the MAF of the repair scheme S-14 becomes $1450 \mathrm{MW}$, instead of $2271 \mathrm{MW}$ in the normal scheme, which with a high probability will lead to a power deficit of $4 \mathrm{~S}$ during the hours of maximum power consumption. During the initial analytical analysis of the situation with the failure of the power transmission line, it can be 
determined that the influence of this power transmission line on the probability of deficit-free operation in $4 \mathrm{~S}$ will be $1-0.00324=0.9968$, which coincides with the probability of deficiency-free operation, determined when adequacy assessment. Thus, in the course of adequacy assessment of the UES of Russia in a number of considered design states in the $4 \mathrm{~S}$ reliability zone, power shortages were determined.

3. Reliability zone $1 \mathrm{U}(\mathrm{U}$ - Ural) includes a part of the power system of the Yamalo-Nenets Autonomous Okrug with the capture of a part of the Vankor power region of the Krasnoyarsk Krai. The probability of deficit-free work in the $1 \mathrm{U}$ reliability zone turned out to be 0.9989 , which is slightly lower than the accepted standard. The own maximum power consumption of the $1 \mathrm{U}$ reliability zone is $945.9 \mathrm{MW}$, the available capacity is $1019.8 \mathrm{MW}$. 1U has a surplus of its own generating capacity, which is equal to 73.9 MW. The $1 \mathrm{U}$ reliability zone is connected only with the $2 \mathrm{U}$ reliability zone with a controlled section $\mathrm{U}-33$, which includes three $220 \mathrm{kV}$ power lines, the MAF of the normal U-33 circuit in the $1 \mathrm{U}$ direction is $48 \mathrm{MW}$. In fig. 3 shows the balance of power $1 \mathrm{U}$ and the adjacent reliability zone.

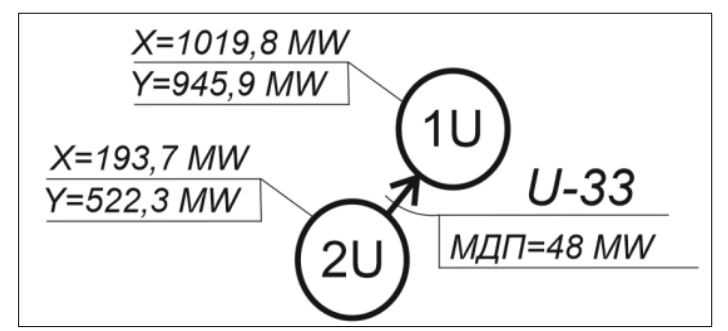

Fig. 3. Power balance of $1 \mathrm{U}$ and adjacent reliability zone.

Since the reliability zone $2 \mathrm{U}$ and the subsequent $3 \mathrm{U}$ are in short supply, the transfer of power to compensate for a possible power deficit in $1 \mathrm{U}$ is unlikely. MAF of the controlled section U-33 is low, and in repair schemes it is equal to zero, which can also prevent compensation of the power deficit in $1 \mathrm{U}$. In $1 \mathrm{U}$ at Urengoyskaya power station there are three large generating units, the capacity of each is more than $150 \mathrm{MW}$, and the accident rates are 0.00925 , 0.00007 and 0.00030 . The failure of each of the generating units leads to the failure of the entire station, thus the integral probability of failure of a system of three generating units is 0.00962 , and, accordingly, the probability of deficiency-free operation in the $1 \mathrm{U}$ reliability zone during the period of maximum power consumption can be defined as $1-0.00962=0.99040$, which led to the values of reliability indicators below the standard level.

4. Reliability zone 9E (E - East) includes a part of the power system of the Amur Oblast and a part of the power system of the Zabaykalsky krai. The probability of deficiency-free operation in the 9E reliability zone turned out to be 0.9987 , which is slightly lower than the accepted standard. The 9E reliability zone does not have its own generation, its own maximum power consumption is 92.3 MW. When carrying out the calculations, it was assumed that the power lines on the western side are constantly open. On the east side, $9 \mathrm{E}$ is connected to $8 \mathrm{E}$ by two 220
$\mathrm{kV}$ transmission lines, which are included in the controlled section E-9 with MAF 215 MW in normal and repair schemes. The adjacent $8 \mathrm{E}$ reliability zone also does not has its own generation. In fig. 4 shows the balance of power $9 \mathrm{E}$ and adjacent safety zones.

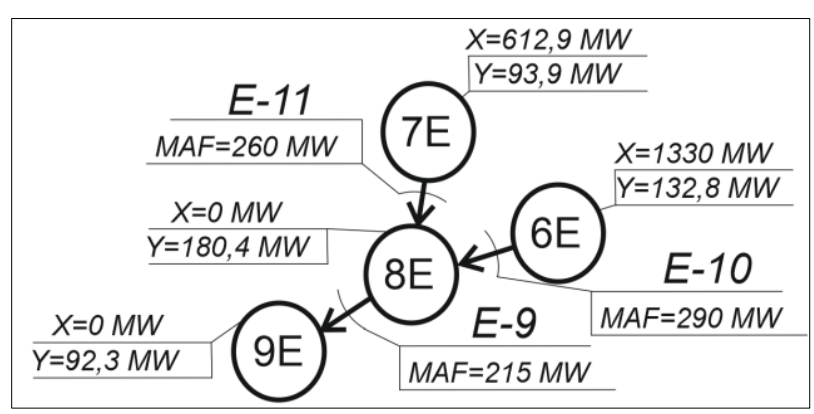

Fig. 4. Power balance of $9 \mathrm{E}$ and adjacent reliability zones.

There is no own generation in the 9E reliability zone and the only adjacent $8 \mathrm{E}$ reliability zone. For this reason, ensuring adequacy in these zones is entirely dependent on the operability of the transmission lines that connect these zones with the rest of the East IPS. Reliability zone $8 \mathrm{E}$ is connected to reliability zones $6 \mathrm{E}$ and $7 \mathrm{E}$, which have a surplus of generating capacity at the level of $1700 \mathrm{MW}$. Thus, having studied the balance situation of the energy region under consideration, we can conclude that power shortage in 9E arise due to failures of the power lines of the E-10 and E-11 controlled sections.

Further, calculations were made to optimize the generating capacity reserve in accordance with the statement of problem (1) - (3). At the same time, the standard value of the probability of deficit-free work was adopted at the level of 0.999 . Table 3 shows the calculated data on the power balance of the UPS of Russia per hour of the coincident maximum power consumption in 2022 for the options for ensuring the standard level of probability of deficit-free operation at the level of 0.999 , taking into account the conclusions of generating capacities. Table 4 presents the results for IPS of Russia.

Table 3. Power balance in the UPS of Russia at the level of 2022()

\begin{tabular}{|c|c|}
\hline Installed capacity, MW & 183902 \\
\hline $\begin{array}{c}\text { Generation capacity disconnection, } \\
\text { MW }\end{array}$ & 34198 \\
\hline $\begin{array}{c}\text { Coincident maximum power } \\
\text { demand, MW }\end{array}$ & 165202 \\
\hline Capacity reserve, \% & 11,3 \\
\hline
\end{tabular}


Table 4. Power balance in the UPS of Russia at the level of 2022()

\begin{tabular}{|c|c|c|c|c|}
\hline $\begin{array}{c}\text { EPS } \\
\text { Name }\end{array}$ & $\begin{array}{c}\text { Available } \\
\text { capacity, } \\
\text { MW }\end{array}$ & $\begin{array}{c}\text { Generation } \\
\text { capacity } \\
\text { disconnection, } \\
\text { MW }\end{array}$ & $\begin{array}{c}\text { Coincident } \\
\text { maximum } \\
\text { power } \\
\text { demand, } \\
\text { MW (with } \\
\text { UPS of } \\
\text { Russia) }\end{array}$ & $\begin{array}{c}\text { Capacity } \\
\text { reserve, } \\
\%\end{array}$ \\
\hline $\begin{array}{c}\text { Nord- } \\
\text { West } \\
\text { IPS }\end{array}$ & 19960 & 5674 & 16470 & 21 \\
\hline $\begin{array}{c}\text { Central } \\
\text { IPS }\end{array}$ & 38094 & 5703 & 37120 & 5,6 \\
\hline $\begin{array}{c}\text { South } \\
\text { IPS }\end{array}$ & 18810 & 2984 & 17840 & 5,4 \\
\hline $\begin{array}{c}\text { Middle } \\
\text { Volga } \\
\text { IPS }\end{array}$ & 19562 & 5619 & 16953 & 15,4 \\
\hline $\begin{array}{c}\text { Ural } \\
\text { IPS }\end{array}$ & 43690 & 7619 & 38820 & 12,5 \\
\hline $\begin{array}{c}\text { Siberia } \\
\text { IPS }\end{array}$ & 35090 & 3454 & 31483 & 11,5 \\
\hline $\begin{array}{c}\text { East } \\
\text { IPS }\end{array}$ & 8696 & 3147 & 7137 & 21,8 \\
\hline
\end{tabular}

After the calculations, in which the generating capacities were disconnected, it was determined that to ensure the probability of deficit-free operation in the reliability zones of the UES of Russia at the level of 0.999 , $183,902 \mathrm{MW}$ of available capacity is sufficient, of which $18,700 \mathrm{MW}$ are reserves of various types.

It can be seen from table 4 that the distribution of generating capacity reserves calculated of IPSs is rather uneven. This is due to the strong ties between the zones of reliability of neighboring IESs, which make it possible to redistribute redundancies of generating capacity between zones of reliability, including between different IPS, and to carry out power flows to maintain the required level of adequacy. So, you can see that, for example, in the Central IPS, the value of the reserve of generating capacity is low, in this case, ensuring the standard level of probability of deficit-free operation in the Central IPS depends on power flows from other IPSs. The high level of redundancy in the East IPS is explained by the specifics of the structure of generating capacities. In the power balance of East IPS there are about $40 \%$ of hydroelectric power stations, the output of generating units of which was not carried out when determining the reserves of generating capacity corresponding to the standard values of the probability of deficit-free operation. This condition influenced the level of redundancy of the East IPS.

\section{Conclusion}

Determination of the rational level of generating capacity reserve in modern conditions of long-term planning of the development of power systems is a mandatory procedure and should be carried out when drawing up development plans for the UPS of Russia. The rational level of generating capacity reserve is determined when solving the optimization problem. For different conditions of the functioning and development of the power system, the optimization problem can have different target functions and a set of restrictions. In modern conditions of development, the UPS of Russia has accumulated a significant redundancy of generating capacities that have exhausted their resource. Under these conditions, the objective function of the optimization problem of determining the reserve of generating capacity can be defined as maximizing the total capacity of the disconnected generating units or minimizing the total capacity of the generating units remaining in operation, subject to the mandatory criterion of adequacy level.

In the article, using the example of the development plans of the UPS of Russia for 2022, the situation with the power balance is analyzed and calculations are carried out to determine the generating capacities, without which it is possible to ensure the probability of deficit-free operation in the reliability zones of the UPS of Russia at the level of 0.999 . In the existing development plans, the probability of a deficit-free operation in almost all reliability zones of the UPS of Russia is higher than the accepted standard, and the generating capacity reserve is at the level of $32 \%$, which is economically inexpedient. During the study, it was found that to ensure the probability of deficit-free operation at the level of 0.999 , it is possible without 34198 MW of generating capacities. As a result, ensuring the adopted standard for the probability of deficit-free operation is possible while maintaining the generating capacity reserve at $11.3 \%$.

The reported study was funded by RFBR, project number 20-08-00550

\section{References}

1. Guidelines for designing the development of power systems. Project. Ministry of Energy of Russia. May 29, 2019 (In Russian)

2. Rudenko Y.N., Cheltsov M.B. Reliability and redundancy in power systems. - Novosibirsk: Nauka, 1974 - 263 p. (In Russian)

3. Wenyuan Li Probabilistic Transmission System Planning. Wiley-IEEE Press. 2011. 376 p.

4. Krupenev D.S., Perzhabinsky S.M. The problem of optimizing the adequacy of electric power systems. Digest: Methodological issues in the study of the reliability of large energy systems. 2013. P.462-469. (In Russian)

5. Krupenev D.S., Kovalev G.F. Reliability evaluation of the links of the main structure of electric power systems. Risk analysis problems. 2010. T. 7. No. 3. P. 34-39. (In Russian)

6. Decree of the Government of the Russian Federation of December 27, 2010 N 1172 (as amended on June $30,2020)$ "On approval of the Rules for the wholesale electricity and capacity market and on amendments to some acts of the Government of the Russian Federation on the organization of the functioning of 
the wholesale electricity and capacity market". (In Russian)

7. The concept of ensuring reliability in the electric power industry / Ed. under the editorship of Voropay N.I., Kovalev G.F. Publishing House "Energy", 2013. $301 \mathrm{p}$.

8. Krupenev D.S. Assessment of Power System Adequacy with Renewable Energy Sources and Energy Storage Systems // E3S Web of Conferences. Vol.58. ID: 01012 2018. DOI: 10.1051/e3sconf/20185801012

9. Kovalev G.F., Lebedeva L.M. Reliability of Power Systems. / Springer. 2019. 237 p.

10. Billinton R., Allan R.N. Reliability Evaluation of Power Systems. - Plenum Publishing (New York), 1996. $-540 \mathrm{p}$.

11. Belyaev N.A., Korovkin N.V., Wonderful V.S. Calculation of indicators of power systems adequacy taking into account the variable topology of the electrical network. Electricity. 2016. No. 4. P. 4-10. (In Russian)

12. Lebedeva L.M., Kovalev G.F., Krupenev D.S. Electric power systems adequacy standardization and formation of generating capacity reserve // Reliability and safety of power engineering. T.11.\# 1. 2018. P. 413. (In Russian)

13. Markovich I.M. Modes of energy systems. - Moscow: Science. - 1986, 252 p. (In Russian)

14. Order of the Ministry of Energy of Russia dated 02.28.18 No. 121 "On approval of the scheme and development program for the Unified Energy System of Russia for 2018 - 2024" (In Russian)

15. Methodological recommendations for the design of the development of power systems / CO 15334.20.118-2003, Approved by order of the Ministry of Energy of Russia dated June 30, 2003 No. 281э. (In Russian) 